\title{
The Original Banana Split: Multi-disciplinary implications of the generation of African and Pacific Plantains in Island Southeast Asia
}

\author{
Edmond De Langhe, Xavier Perrier, Mark Donohue, \\ and Tim Denham
}

\section{Research}

\begin{abstract}
Traditional starchy banana cultivation in the humid tropics is dominated by two widespread, but geographically discrete, groups of $A A B$ cultivars: plantains in Africa and maoli-popo ulu in the Pacific. Both $A A B$ subgroups exhibit exceptionally high cultivar diversity due to multiple somatic mutations, and yet both subgroups have relatively similar genetic origins. Although both cultivar groups originated within a region defined by the Philippines, Eastern Indonesia, and New Guinea, the precise area of origin for each $A A B$ group within this region is different. Significantly, the distribution of each sub-group is mutually exclusive: traditional cultivation of maoli-popo ulu cultivars is not attested to the West of the region and of plantain cultivars to the East. On the basis of botanical data, we argue that the original plantain hybrids were probably formed in the Philippines, while basic maoli-popo ulu were formed in the Bismarck Archipelago and the Solomon Islands. The generation of these two AAB subgroups shed light on human interactions within Island Southeast Asia before 3000 cal BP, for which there is currently only limited archaeological evidence.
\end{abstract}

\section{The Banana "Split" and Its Historical Implications}

Traditional starchy banana cultivation in the humid tropics is dominated by two very diverse subgroups of cultivars, especially in Africa and Oceania: 'AAB plantain' (Figure $1 \mathrm{~A})$ and 'AAB maoli-popo 'ulu' (Figure 1B). Both cultivar subgroups are triploid hybrids of Musa acuminata Colla (A) and Musa balbisiana Colla (B). We adopt here the acronyms "P" for the AAB plantain-subgroup and "MP" for the $A A B$ maoli-popo ulu subgroup. Other traditional $A A B$ exist in Oceania, especially in New Guinea, but these are not nearly so popular and widespread as MP (Simmonds 1959:102-106).

The geographical distribution of traditional $P$ cultivation is characterized as follows: extremely high diversity in Africa, very low diversity in South India, almost no diversity in mainland and Island Southeast Asia (ISEA), and near absence in Oceania. In sharp contrast, the MP distribution is strictly confined to Oceania, where it shows maximum diversity in Melanesia. Thus the respective P and MP domains are exclusive, with the division running from just east of the Philippines to just west of New Guinea (Figure 2): no traditional $P$ diversity is found east of the border and no MP cultivars exist to the west. This is surprising because both subgroups are closely related genetically and both have their origin in the same broad region, roughly defined by the Philippines, Sulawesi, and New Guinea (Perrier et al. 2009, 2011), which we call hereafter "the

\section{Correspondence}

Edmond De Langhe, Laboratory of Tropical Crop Improvement, Katholieke Universiteit Leuven, Kasteelpark Arenberg 13-3001 Heverlee, BELGIUM. edmond.delanghe@chello.be

Xavier Perrier, CIRAD (Centre de cooperation internationale en recherche agronomique pour le développement), Avenue Agropolis - TAA-75 / 02 - 34398 Montpellier Cedex 5, FRANCE. xavier.perrier@cirad.fr

Mark Donohue, Research School of Pacific and Asian Studies, Australian National University, ACT 0200, AUSTRALIA. mark@donohue.cc

Tim Denham, School of Geography and Environmental Science, Monash University, Clayton VIC 3800, AUSTRALIA. tim.denham@anu.edu.au

Ethnobotany Research \& Applications 14:299-312 (2015)

Published: 25 November 2015 

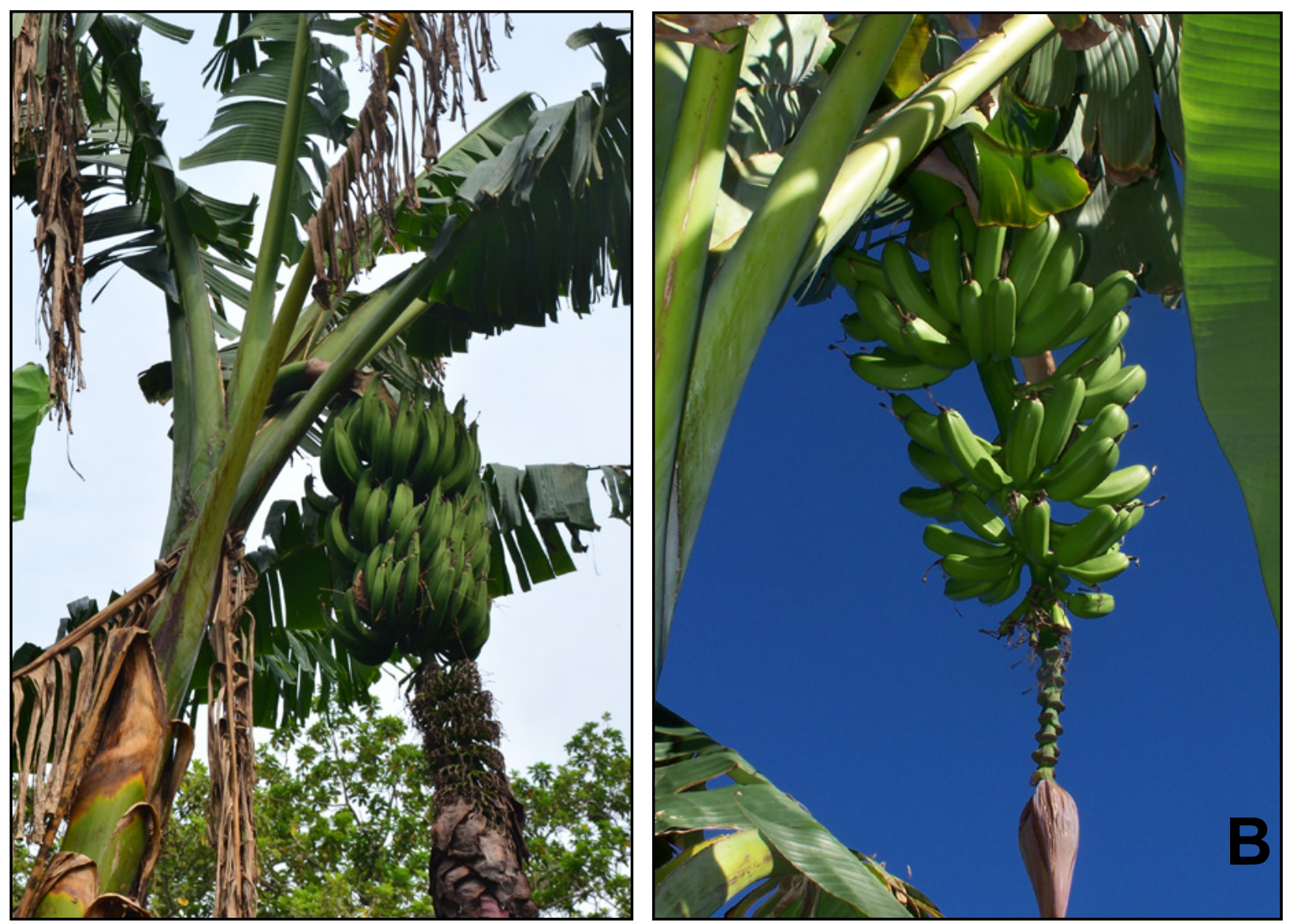

Figure 1. Typical plantain (P subgroup) and maoli-popo ulu (MP subgroup) cultivars. A. Plantain litete. Courtesy J. Adheka. B. Maoli feta'u hina. Courtesy A. Kepler.

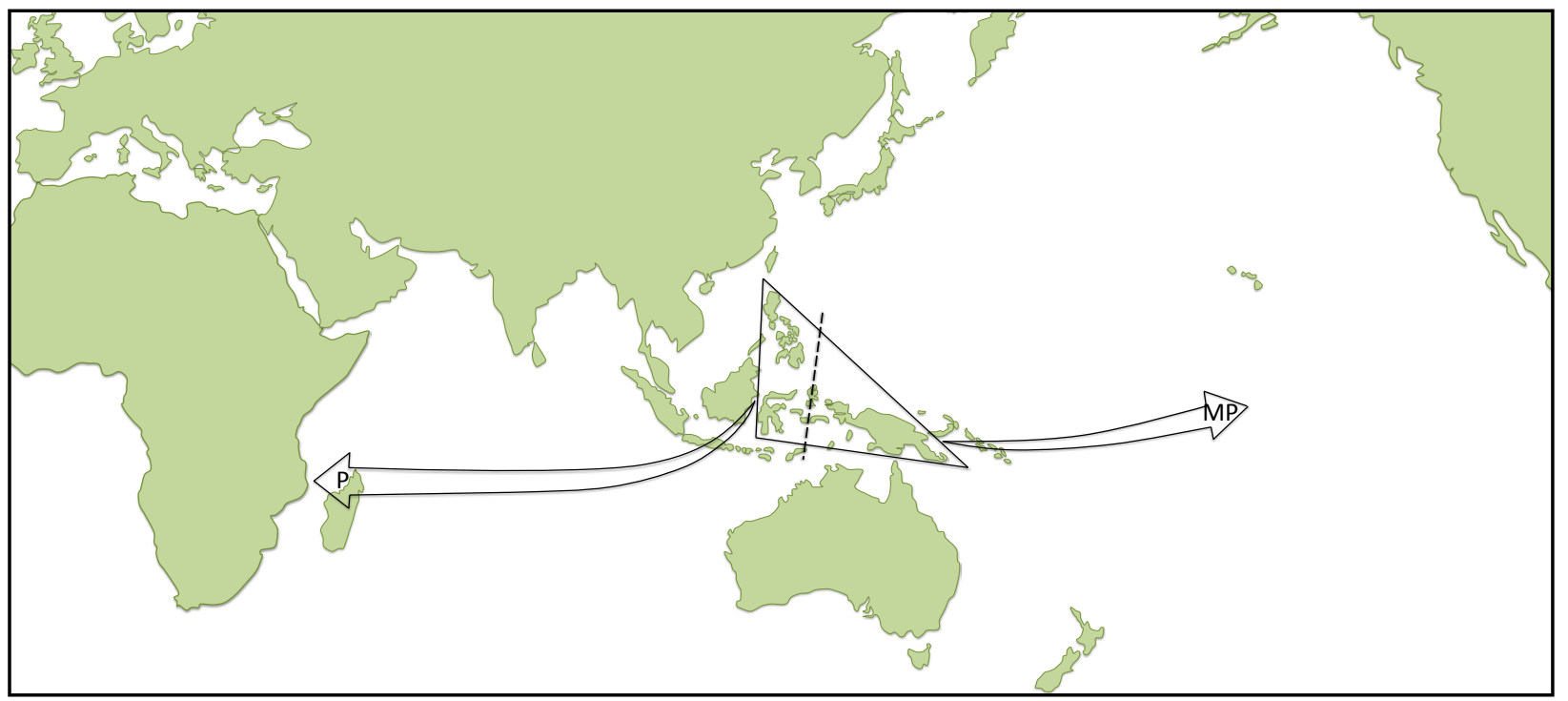

Figure 2. African and Oceanian diffusion for plantain $(P)$ and maoli-popo ulu (MP) AAB bananas from the triangle PSNG (Philippines, Sulawesi, and New Guinea). The dashed line is the boundary between P/MP. 


\section{De Langhe et al. - The Original Banana Split: Multi-disciplinary implications of the generation of African and Pacific Plantains in Island Southeast Asia}

PSNG triangle" (Figure 2). Based on their mutually exclusive geographical distributions, the initial cultivars for both groups were almost certainly generated in two separate parts of this region, most likely as a product of two distinct domestication and hybridization processes. The two cultivar subgroups ( $P$ and MP) subsequently underwent different propagation and dispersal histories, again due to distinct human-plant domesticatory relationships.

Given that both $\mathrm{P}$ and MP were generated within the PSNG triangle, the exclusive geographical distributions of the two major cultivar groups have potential to shed light on broader historical processes within that region during the mid-to-late Holocene, primarily around c. 4000-2500 years ago. For instance, archaeobotanical, botanical, and genetic evidence indicates that $P$ were generated in ISEA and were likely spread under cultivation to West Africa by 2790-2300 cal BP (De Langhe 2007, De Langhe \& de Maret 1999, Mbida et al. 2000, Perrier et al. 2011). Similar lines of multidisciplinary evidence suggest MP were generated and dispersed eastwards from the Bismarck Archipelago into uninhabited archipelagos of Remote Oceania after c. 3100 cal BP (Denham et al. 2012, Kennedy 2008).

Genetic studies have enabled some of the stages in the historical processes leading to the generation of AAB hybrids. Erratic meiosis in edible AA cultivars can produce diploid (AA) gametes, which in the proximity of $M$. balbisiana can fuse with $B$-gametes to form $A A B$ zygotes (Simmonds 1962). These sterile AAB plants survive and are spread through vegetative propagation, if found useful by people. In the case of both $\mathrm{P}$ and MP, the edible AA were derived from the $M$. acuminata subspecies banksii N.W.Simmonds, which is endemic to New Guinea and around (De Langhe et al. 2009, Perrier et al. 2011). It has been proposed that $P$ and MP were among the first of the various $A A B$ cultivar subgroups to be generated, before the formation of other AAB on mainland Eurasia (De Langhe \& de Maret 1999, Perrier et al. 2009). It has been demonstrated (De Langhe 2009) that the original areas of contact between $M$. balbisiana and edible AAs that led to the generation of $\mathrm{P}$ and MP can be situated in the abovementioned PSNG triangle.

The problem is to find out why, how, and when the initial $P$ and MP could have been formed in two distinct parts of the triangle and subsequently dispersed over vast and geographically exclusive regions in the past ${ }^{1}$.
Fundamental to any such historical interpretation is consideration of the origins and movements of the B-genome ( $M$. balbisiana) and AA-genome (derived from $M$. acuminata subspecies) within ISEA-New Guinea in order to identify places where $A$ and $B$ genomes were present together, a prerequisite for the generation of $A A B$ triploids. Only then is it possible to identify the likely source areas for the separate generation of $\mathrm{P}$ and MP, and to consider the cultural and historical associations for the widespread human-mediated dispersal of the respective $A A B$ cultivar groups. These historical reconstructions are effectively hypotheses drawing upon the existing multidisciplinary evidence; they will require refinement as new data come to the fore.

\section{Tracking Musa balbisiana (Figure 3)}

Musa balbisiana was introduced south of the Philippines. The natural distribution of $M$. balbisiana on continental Asia is confined to rather mountainous areas and stretches from East India to Yunnan (China). The Philippines is commonly included within its natural range, a point which will be revisited below. It is a drought-resistant species that was introduced to lower altitudes in ancient times. It is mainly for fiber production (Simmonds 1956b), although it has numerous uses (Kennedy 2009). Wherever M. balbisiana is (semi-)cultivated it remains a vigorous plant that readily establishes feral populations following introduction. These feral populations are often considered by local people to be "wild," as demonstrated here for the relatively recent historical introduction to the Ryukyu Islands (see below).

In the New Guinea region, Simmonds (1956a) recorded $M$. balbisiana on the Gazelle Peninsula of New Britain (three locations) and in Morobe Province on mainland Papua New Guinea (three locations). During his extensive study of Musa species growing in PNG, Argent (1976) observed populations or scattered plants in eight places in Morobe Province, one in Madang Province, and one in Northern (Oro) Province. An extensive banana exploration mission in the late 1980s (Sharrock 1990) documented only two M. balbisiana plants on New Britain and at three locations in Madang Province (mainland $\mathrm{PNG}^{2}$ ). On New Britain, it was noted that the species was "previously reported as being common but is now rare" (Sharrock 1990:152). On a recent tour of the area by a member of the 1980s mission, no trace of the species was found at any of these locations, and he had the same frustrating experience on

1. Even in modern times, only a couple of cultivars of $P$ and MP seem to have been introduced into each other's geographical areas. In Indonesia, two MP cultivars have been observed in private gardens (Hermanto et al. 2014b), while the P (horn plantain) has been observed by Simmonds in Samoa, for example, where it was classified by him as "a fairly recent introduction" (Simmonds 1959:104).

2. "PNG" is used to refer to the country of Papua New Guinea, the independent state comprising the eastern half of the island of New Guinea and various adjacent islands, in which numerous banana collecting expeditions have occurred. By contrast, the term "New Guinea" is used to refer to the entire island or the region. 


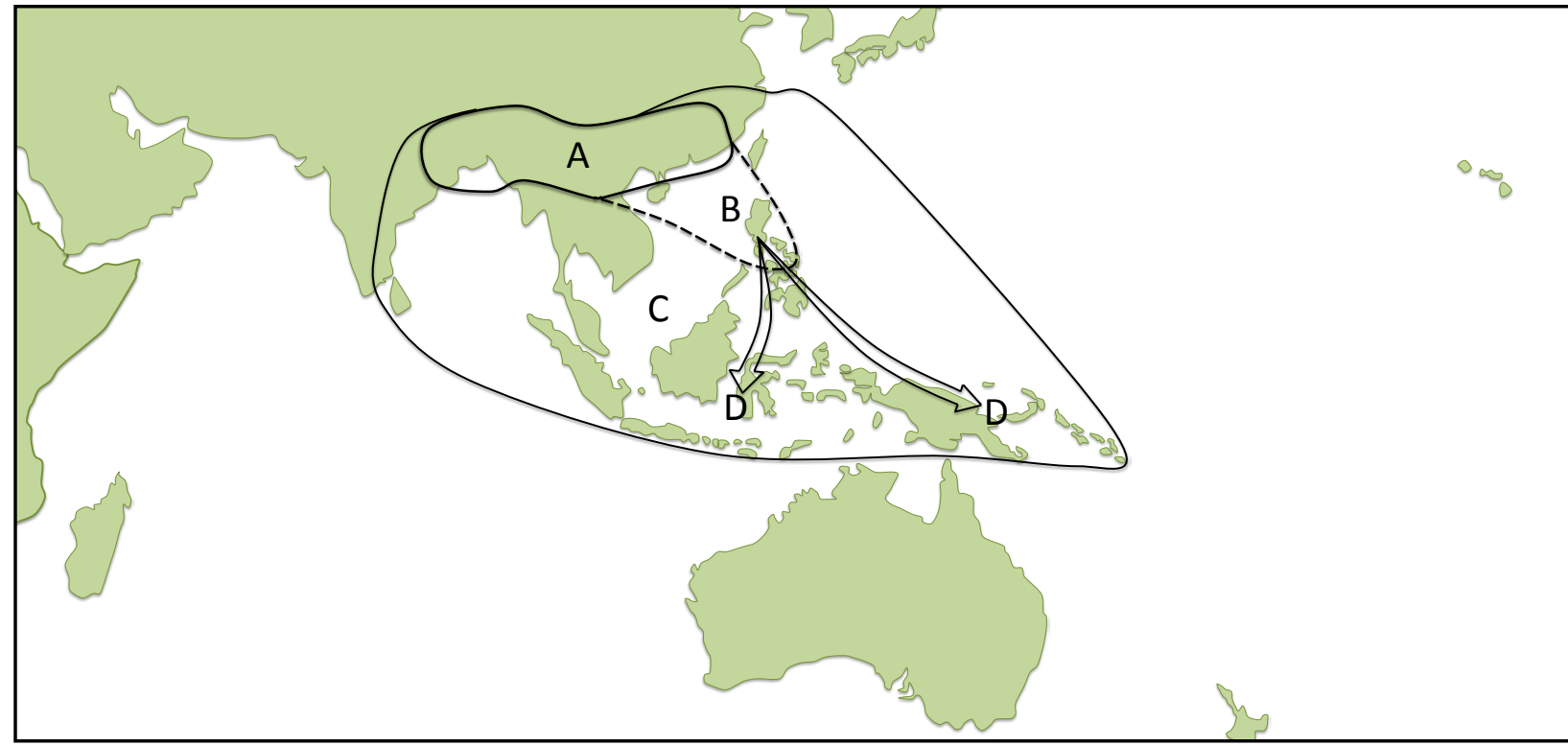

Figure 3. The regions of Musa balbisana Colla presence: (A) original habitat of wild Musa balbisiana Colla; (B) questioned area of wild $M$. balbisiana; (C) feral $M$. balbisiana domain; and arrows leading to (D) $M$. balbisiana meeting the edible Musa acuminata Colla AA subspecies.

mainland $\mathrm{PNG}^{3}$. At present, comparable surveys of wild bananas have not been undertaken in western New Guinea, which is part of present-day Indonesia. Based on the surveys undertaken, Argent (1976:86-87) argues for human introduction of $M$. balbisiana to New Guinea.

The rather scattered distribution of $M$. balbisiana in PNG is unexpected for such a vigorous species. The rare plants could be vestiges of more widespread populations in the past. They are still used by people; namely, they have continued cultural significance, e.g., for wrapping food (Sharrock 1990:152). However, it should be noted that these stands of $M$. balbisiana occur in northern coastal provinces of mainland New Guinea and New Britain ${ }^{4}$. If the species was native to New Guinea, why is the plant not more widespread within the flora of the region?

Nowhere in Indo-Malaysia have large feral or "wild" populations of $M$. balbisiana been reported. Simmonds (1956b:473) states "the limited distribution of the 'wild' plant suggests to me that the species was introduced to Java and became locally naturalized there. There is no evidence at all of its occurrence in Borneo...". The ab- sence of the plant on Borneo was recently reaffirmed after a collecting expedition there failed to locate any specimens $^{5}$. Wild populations of $M$. balbisiana are also absent from Sumatra ${ }^{6}$ and eastern Indonesia, including Sulawesi, Maluku, and the Lesser Sunda islands (Hermanto et al. 2014a,b).

In conclusion, the concept of a natural presence of $M$. balbisiana across southern ISEA and New Guinea is untenable based on the available botanical evidence of its "wild" range. The possible exception is the Philippines, where it is abundant. Thus, at first glance, the Philippines would appear to be the most likely region of origin for M. balbisiana in ISEA. This, however, turns out to be unlikely.

\section{Musa balbisiana is probably not native in the Philippines}

Paul Allen, a botanist who spent eight months studying banana diversity in the Philippines, states (1965:368) "[M. balbisiana is] a common species, found in all of the major islands in the Philippines, where it occurs on stream banks, along roadsides and on cutover lands from sea

3. Jeff Daniells, pers. email comm. to De Langhe (2-12-2012).

4. Although these coastal regions can be subsumed, in general terms, to regions in which Austronesian languages are spoken today, the distribution of $M$. balbisiana is here discussed in geographical terms only. This is partly because the adoption of Austronesian languages in some of these places in the New Guinea vicinity is likely to have only occurred within the last 2000 years (e.g., Donohue 2007, 2013, Donohue \& Denham in press a,b), and partly because numerous non-Austronesian lineages are also found in this same area.

5. Markku Hakkinen , pers. email comm. to De Langhe (2006).

6. Agus Sutanto, pers. oral comm. to De Langhe (12-12-2013). 


\section{De Langhe et al. - The Original Banana Split: Multi-disciplinary implications of the generation of African and Pacific Plantains in Island Southeast Asia}

level to about $3000 \mathrm{ft}$ in elevation." He continues (same page), "Wild populations show a considerable amount of variation in plant size, and in fruit shape and color, but fall fairly well into two basic types which have distinguishing local names." The two M. balbisiana-types have been confirmed by the Philippine Musa taxonomist Valmayor (Valmayor et al. 2002), and given the descriptive names butuhan (meaning "seedy" in Tagalog) and pacol (unknown derivation). Butuhan is a vigorous, tall plant with large bunch and (rather large) beak-formed fruit; pacol is smaller with densely-packed hands of (short) plump, pyramidally-pointed fingers. Of note, in Indonesia pisang klutuk is a rare $M$. balbisiana very similar to butuhan, and the pacol-type has not been reported (Sutanto \& Edison 2005).

Musa balbisiana populations in the Philippines contain variants with degrees of seed sterility. Pacol frequently produces many soft seeds and sterile seeds. Semi-wild stands of pacol are maintained by subsistence farmers (Valmayor et al. 2002). A comparable, but less pronounced sterility state is observed among the "butuhan" populations according to Allen (1965), who mentions that such fruits are eaten, usually in an immature state before the seeds have hardened. Both Allen (1965) and Valmayor et al. (2002) report various other uses of the M. balbisiana plants in the Philippines, including the cooked male bud as vegetable, vinegar manufacture from fermented ripe fruits, strips of the pseudostem for the manufacture of coarse mats, leaves for wrapping, and so on (also see Kennedy 2009).

As an aside, while Musa textilis Née, by far not so common as $M$. balbisiana and more confined to the highlands in the wild, is the original source of the abaca fiber in the Philippines, M. balbisiana is frequently used as well. This creates confusion with the application of the abaca-name: "plants illustrated as this species (M. textilis) are very frequently [in reality] Musa balbisiana" (Allen 1965:376). Since the pseudostems of the ABB cultivars are very similar, these are also used for fiber-making after the fruits have been collected (Hendrickx 2007:174).

A Philippine origin for $M$. balbisiana is problematic for several reasons. If the species is natural there, multiple $A A B$ cultivar subgroups would have formed as soon as edible AA were domesticated or introduced from further south. However, AAB cultivar diversity is limited in the Philippines, when compared with that in India for example. All dessert $A A B$ subgroups, and even some dessert $A B B$, appear to be introductions in relatively recent times mostly from India, directly or indirectly via Java (Valmayor et al. 1981). Apart from these relatively recent introductions, one rather typical 'Philippine' AAB subgroup is present: laknau, which is genetically related to plantains. Regarding $\mathrm{P}$, the cultivar tundoc, which is morphologically similar to the Horn type of plantains, is present, yet rare like elsewhere in Asia. Furthermore, a few accessions, morpho- logically similar to the French type of plantains are restricted to, or are proximal to, the remote Aeno peoples, such as those near Mount Pinatubo, together with a couple of very rare, starchy $A A B$. As for the MP, they are totally absent from the Philippines.

While there are linguistic indications that pre-Austronesian Philippine populations were familiar with $M$. textilis and $M$. acuminata, the evidence for engagement with $M$. balbisiana is lacking. Negrito and Negrito-like populations in the Philippines apply terms derived from *qaRutay to only two of the three wild banana species: M. acuminata subspecies. errans (Blanco) R.V.Valmayor and-occasionally $-M$. textilis. Terms relatable to the reconstructions *baRat, *sagin, and *sab?a are applied to edible bananas in most of the Philippine Austronesian languages; they appear in Philippine Negrito communities as borrowed terms (Donohue \& Denham 2009, Reid 1994).

On balance, there are several lines of evidence suggesting that $M$. balbisiana is not native to the Philippines. It has been intensively used and semi-cultivated there for a long time, which accounts for its almost ubiquitous presence. If $M$. balbisiana was introduced to the Philippines, where was its likely origin: Taiwan to the north or mainland Southeast Asia to the west? Southern or eastern sources are unlikely based on present-day weak distributions of very small and scattered wild populations in southern ISEA and New Guinea, respectively, as discussed above.

\section{Musa balbisiana is probably not native to Taiwan}

Taiwan seems an attractive possibility for the origin of the Philippine M. balbisiana because of its proximity and longterm historical connections (Piper et al. 2009). However, the presence of $M$. balbisiana on Taiwan is disappointingly meager. According to the horticulturist Markey (2009) the species is common in the south, including "in the wild," is very scarce on the rest of the island, and is absent along the eastern side. The near-absence of wild BB beyond the southern tip of Taiwan is not accounted for by a less hospitable climate since the plant thrives under less favorable climatic conditions in the Ryukyu Islands further north. Indeed, the plant was recently classified as a newly naturalized wild banana to Taiwan by taxonomists (Chiu et al. 2007). Consequently, and given its preponderance in southern Taiwan, the species was most probably introduced to Taiwan from the Philippines, rather than having been introduced from Taiwan to the Philippines.

\section{The Ryukyu Islands exemplify rapid naturalization of M. balbisiana}

It is only now being widely recognized that the famous Musa basjoo on the Ryukyu Islands (cf. the basjoo-fuu fiber in Japanese) is not the $M$. basjoo of South China, but in fact $M$. balbisiana (Kennedy 2009:190). This fact was already established in 1975 by the Japanese bota- 
nist Hatusima (Constantine 2007). It has convincingly been demonstrated that the plant did not exist on these islands before the $15^{\text {th }}$ century (Hendrickx 2007). Based on an analysis of a considerable number of written sources, Hendrickx (2007) concluded that the traditional fiber was made from the ramie (Boehmeria nivea (L.) Gaudich.) and that the first contacts with the Chinese Ming dynasty (early 16th century) stimulated the introduction of $M$. balbisiana from China. There were great economic benefits for the Ryukyus, including an intensive trade of excellent banana fiber cloths with China, Korea, and Japan during $17^{\text {th }}-19^{\text {th }}$ centuries. Of particular relevance is Hendrickx's observation that the introduced species grows abundantly in forests on the hills of Iriomote Island at the southernmost tip of the archipelago, so that local people consider the plant to be indigenous there. Thus, a vigorous Musa species, such as M. balbisiana, if actively (semi-)cultivated for only a couple of centuries in rather temperate climates, can rapidly develop extant, "wild-looking" populations.

\section{The history of M. balbisiana in ISEA and New Guinea}

The botanical evidence, including a relatively recent introduction to the Ryukyu Islands, sheds a new light on the history of $M$. balbisiana in ISEA and the New Guinea region. The available data point to a naturalized state of the plant, even in the Philippines. Once introduced to a suitable environment and potentially (semi-)cultivated there for a period of only a few centuries, the plant is able to rapidly establish feral (or "wild-looking") populations and become widespread, as seen following its introduction to the Philippines, southern Taiwan, and Ryukyus. The absence of wild or feral populations of M. balbisiana in Borneo, most of Indonesia, and large parts of the New Guinea region suggests that the plant is not native to those areas and that there have only been localized introductions under cultivation. Of note is the likely introduction of $M$. balbisiana to New Britain and the north coast of New Guinea.

Current evidence suggests that people most likely introduced $M$. balbisiana from mainland Southeast Asia to the Philippines. The species probably became well-established in the Philippines before dispersing elsewhere in ISEA. Indeed, rather than being introduced to the Philippines from Taiwan, it is more likely that the opposite is true, that the plant was introduced to Taiwan from the Philippines, although this hypothesis awaits genetic confirmation. The great distance from mainland Southeast Asia to the Philippines poses the question of who undertook this voyage over such a long distance? There were certainly contacts across the Batanes Strait between southern Taiwan and northern Luzon at least 4000 years ago (Hung et al. 2007, Piper et al. 2009), with subsequent colonization of the Mariana Islands from the Philippines by c. 3500 years ago (e.g., Hung et al. 2011). From c. 2500-1500 years ago, nephrite artifacts shed light on social connectivities around the South China Sea, embracing regions as distant as Taiwan, Philippines, Vietnam, and Thailand (Hung et al. 2007), with evidence for the spread of Dongson bronze artifacts from Vietnam as far as western New Guinea also likely to date to this time period (Wright et al. 2013). As yet, there is no definitive archaeological evidence for direct connections between mainland Southeast Asia and the Philippines before c. 2500 years ago (though see Bulbeck 2008 for possibilities), but there is some linguistic evidence in the form of banana terminologies for a connection (Donohue \& Denham 2009). However, if $M$. balbisiana was introduced to the Philippines, then it was present there before $\mathrm{P}$ and MP were generated, namely before at least 3100 years ago (when MP are inferred to have spread into the Pacific), and would provide the earliest inferential evidence for direct contact between mainland Southeast Asia and the Philippines.

\section{Tracking the Generation and Dispersal of Edible AA Cultivars}

\section{The distribution of M. acuminata in ISEA-New Guinea}

Several subspecies of $M$. acuminata, the source of the Agenome in most cultivated bananas, are present in a belt from North India, mainland and Island Southeast Asia, to New Guinea (De Langhe et al. 2009). Each subspecies has a discrete geographical range, some of which are mutually exclusive (Figure 4). The main subspecies are clearly differentiated by their nuclear as well as cytoplasmic genomes, enabling the detection of their respective contributions to cultivated diploids and triploids (Perrier et al. 2009, 2011).

Of greatest significance for the generation of $\mathrm{P}$ and MP is M. acuminata subspecies banksii. Allelic frequencies of $P$ as well as MP genomes refer clearly to subspecies banksii as donor of AA genomes in these two AAB subgroups (Carreel 1994). This subspecies is considered to be native to New Guinea and is the most genetically differentiated $M$. acuminata subspecies, due to a strict and ancient geographic isolation. It differs from other subspecies by a higher auto-compatibility explaining a higher homozygosity. These characteristics have been used to propose subspecies banksii as a separate species (Argent 1976). The subspecies is also attested in islands to the east of New Guinea, namely New Britain and Solomons, and in northern Australia to the south (Denham et al. 2009, Simmonds 1956b). Intriguingly, subspecies banksii was also found in Samoa, growing as a common wild plant, especially on lower hill slopes, although Simmonds (1962:23) strongly suggests it was introduced by people. West of New Guinea, wild $M$. acuminata are abundant in Sulawesi and Maluku, and most of them look morphologically like subspecies banksii except for some characteristics of the reproductive organs with possible $M$. acuminata subspecies microcarpa (Becc.) N.W.Simmonds trends (Hermanto et al. 2014a,b). The accession called 'Borneo', reflect- 


\section{De Langhe et al. - The Original Banana Split: Multi-disciplinary implications of the generation of African and Pacific Plantains in Island Southeast Asia}

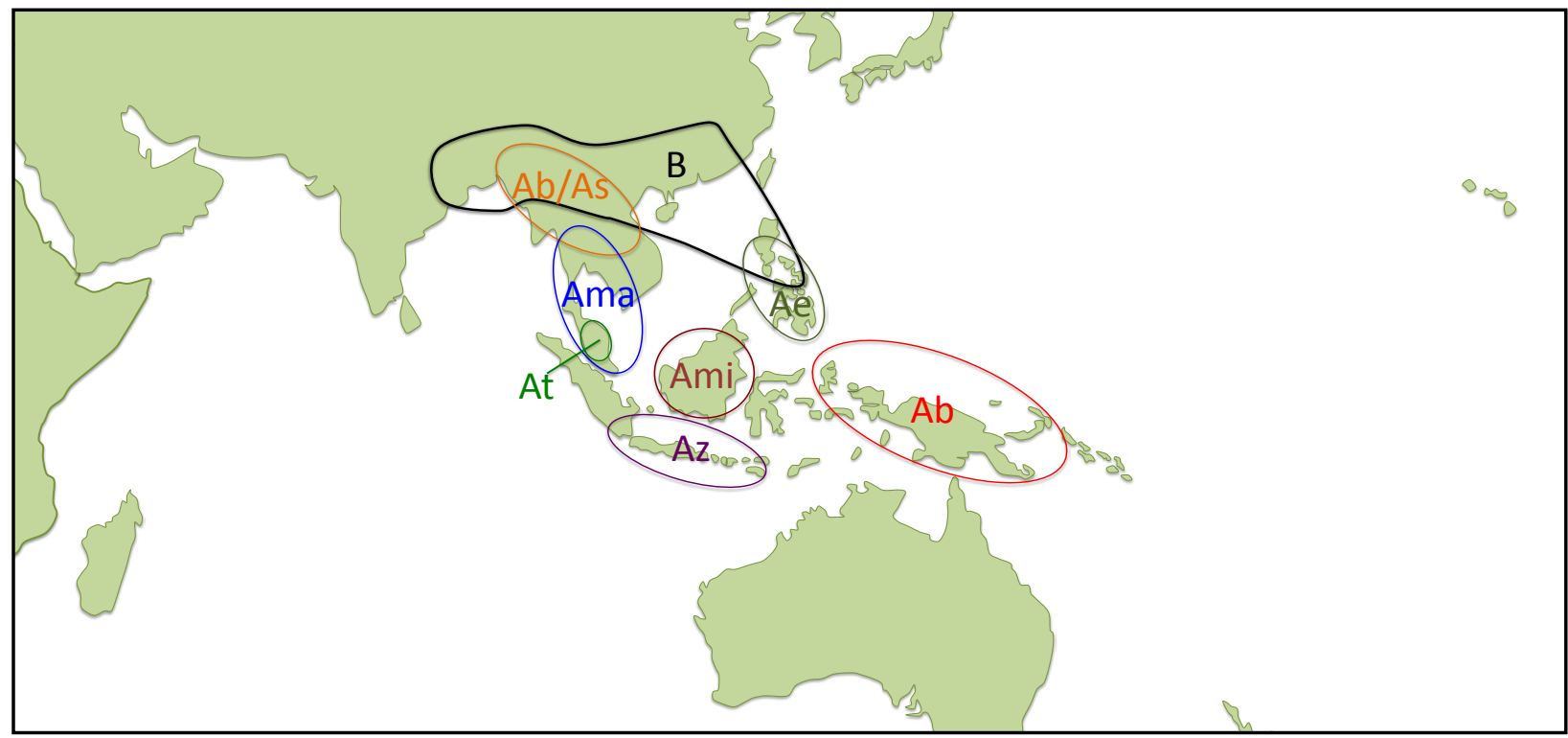

Figure 4. Geographical distribution of (B) Musa balbisiana Colla and subspecies of Musa acuminata Colla: (Ab) subsp. banksii (F.Muell.) N.W.Simmonds, (Ah) subsp. burmanica N.W.Simmonds, (Ae) subsp. errans Argent, (Ama) subsp. malaccensis (Ridley) N.W.Simmonds, (Ami) subsp. microcarpa (Becc.) N.W.Simmonds, (As) subsp. siamea N.W.Simmonds, (At) subsp. truncata (Ridley) Kiew, and (Az) subsp. zebrina (Van Houtte) R.E.Nasution, the wild ancestors of cultivated bananas (from Perrier et al. 2011).

ing its likely origin and regarded as subspecies microcarpa, has a nuclear genome very close to subspecies banksii but with a different cytoplasmic genome (Carreel et al. 2002). Its heterozygosity is higher than subspecies banksii, indicating a hybrid status with subspecies banksii as one parent.

In 1959, Allen surveyed the slopes of Mount Apo on Mindanao island in the Philippines and identified a new $M$. acuminata form, which he called errans, that has since been classified as $M$. acuminata subspecies errans (Allen 1965, Valmayor et al. 2002). During the same survey, Allen identified two other subspecies errans accessions: saguing chongo also on Mindanao and agutay on Luzon. Agutay has a nuclear genome that exhibits a clear subspecies banksii component while the cytoplasmic type is specific and differs from subspecies banksii. Another accession, ITC0343 from UPLB collection in Luzon, has been shown by molecular markers to be similar but not identical to agutay. Hence in the region of East Indonesia and Philippines, populations of wild acuminata showing a subspecies banksii component are suggestive of an ancient northwest expansion of subspecies banksii subspecies from New Guinea.

\section{The generation of edible AA in ISEA-New Guinea}

A whole range of edible AA has been generated within ISEA and the New Guinea region (Perrier et al. 2011). The major domestication signal is parthenocarpy, with seed suppression by sterility and pulp enhancement from the wild forms. The domestication process represents a long period of human selection, perhaps initially for a lot of different purposes and progressively for food, by exploiting latent pulp-enhancement phenotypic traits in some wild acuminata subspecies (Kennedy 2009). These "semicultivated" forms or "cultiwilds" (De Langhe et al. 2009) were generated in the geographic areas within which the main $M$. acuminata subspecies occurred. However, the fully parthenocarpic edible AA, as they exist in the whole of ISEA-NG today, are hybrids associating genomes from two, and sometimes three, different $M$. acuminata subspecies (Perrier et al. 2009). The association of two divergent genomes induces sterility in edible AA. These hybridizations indicate that parental $M$. acuminata subspecies, which were originally geographically isolated, have been brought into contact by people moving between the different regions who transferred initially the cultiwilds and later the fully parthenocarpic edible AA (Perrier et al. 2011).

In terms of the generation of $\mathrm{P}$ and MP, intensive collecting missions in PNG have delivered a large diversity of edible AA subspecies banksii derivatives. Some of them have a nuclear genome very close to wild subspecies banksii and the same cytoplasmic type, including a small number in which the heterozygosity stays low although in most it is markedly increased. For the other edible AA, the subspecies banksii component of the nuclear genome is still present but only the subspecies banksii chlorotype is maintained while the mitotype is similar to edible AA of 
Indonesia and Philippines. Heterozygosity is always high, implying hybridization between distant genomes. In sum, the influence of the subspecies banksii genome appears to have progressively diminished away from the NG region through successive crosses with various other acuminata subspecies as a result of human contacts and exchanges (Perrier et al. 2011).

The area of edible AA subspecies banksii derivatives extends northeast and east of New Guinea, from New Britain and New Ireland around the Bismarck Sea (Arnaud \& Horry 1997) to the Solomon Islands (Daniells 2007) and to Vanuatu (Van Denbrouke, pers. comm. 2014). In Maluku-Halmahera and Sulawesi, several recent accessions exhibit molecular markers that sit within the range of subspecies banksii and derivatives. Others exhibit allelic characteristics specific to $M$. acuminata subspecies zebrina (Van Houtte ex Planch.) Nasution. The area of contact between subspecies banksii and zebrina genomes has already been proposed for the origin of edible $A A$ mshale as well as for AAA mutika, which are today largely present only in East Africa (Perrier et al. 2011).

In the Philippines, the most frequent edible AA are sweet banana $M$. acuminata subspecies. malaccensis (Ridl.) N.W.Simmonds derivatives. However, the accession guyod, found on the slopes of Mount Apo on Mindanao island (Valmayor et al. 2002:94), has a nuclear genome from subspecies banksii and is very close to an AA cultivar found on New Guinea. As for the Philippine AA wild subspecies errans, with which it shares several alleles, its cytoplasmic genome is not of subspecies banksii type, suggesting that it is not a New Guinea-derived variety. Allen described several other AA cultivars that he qualified as "banksii-derivative," or intermediate between subspecies microcarpa or malaccencis and banksii. These accessions have not been genotyped, and their genealogy is unknown; however this cultivar diversity likely reflects a range of cultural influences within the region.

Archaeological investigations at Kuk Swamp in the highlands of PNG indicate that banana cultivation occurred there by at least 6950-6440 cal BP (Denham et al. 2003, 2004, Haberle et al. 2012). The exact nature of the banana plants under cultivation is not known, but they are considered to include M. acuminata-types (Lentfer 2009) and thus specifically subspecies banksii, the only $M$. acuminata subspecies present on New Guinea. Despite the lack of specificity provided by the microfossil evidence in terms of domestication status, the Kuk evidence provides a broad temporal framework for understanding banana cultivation and domestication in the New Guinea region. Additionally, an examination of modern terminologies for bananas (most specifically the proto-term *muku) suggests a "pre-Austronesian" (namely, pre-c. 3500-3000 years ago) extension of bananas westward from New Guinea (Denham \& Donohue 2009, Donohue \& Denham 2009). Taken together with other lines of archaeological, genetic, and linguistic evidence, these findings suggest early cultivation of bananas on New Guinea, with subsequent westward dispersal into eastern Indonesia and eastward dispersal into Near Oceania (Denham 2011, 2013, Perrier et al. 2011).

\section{The P and MP Split: A botanical proposal}

\section{Background}

To review, plantains $(P)$ and maoli-popo ulu (MP) are two cultivar subgroups of $A A B$ triploids, each comprising two A-genomes from the Musa acuminata subspecies banksii (originating in the vicinity of New Guinea) and one B-genome from Musa balbisiana (following De Langhe \& de Maret 1999, De Langhe et al. 2009, Perrier et al. 2011). The quest for understanding the locale and timing of $P$ and MP generation has to take into account (a) the sharp contrast in the presence of $M$. balbisiana between the Philippines and the rest of the PSNG triangle: omnipresent in the Philippines, scarce to absent in the rest; and (b) the genotype of the starchy edible AA-component in $\mathrm{P}$ and MP.

While the variation in the B-genome in the Philippine $M$. balbisiana types butuhan and pacol may have been notable, judging from their diverse morphologies, genetic and morphological variabilities are likely to reduce as subpopulations were successively moved southward. Conversely, wild $M$. acuminata subspecies banksii is omnipresent on New Guinea and surrounding islands, but has not been documented in the Philippines. Starchy edible AA variety banksii derivatives are very minor compared to the mostly sweet edible AA in Philippines, but they are much more common southwards. Based on such botanical information, one can generate hypotheses regarding the origin of the geographically exclusive distributions of $\mathrm{P}$ and MP, namely, to infer the location of the original "banana split."

\section{$P$ was probably formed in the Philippines, but not MP}

Given the wide and intensive presence of $M$. balbisiana in the Philippines, and the fact that starchy edible AA subspecies banksii derivatives were predominantly formed in the subspecies banksii-region to the south, one scenario for $A A B$ generation is that the edible $A A$ were introduced from this "southern" region, namely, northward from Maluku or New Guinea. Although this scenario plausibly accounts for $\mathrm{P}$ formation in the Philippines, it does not fit for MP generation.

A Philippine origin of $P$ appears highly plausible. A few French plantain cultivars have been recorded among $\mathrm{Ne}$ grito-speaking tribes (Allen 1965, De Langhe \& Valmayor 1979) and seem to be vestiges of an ancient past, yet of uncertain antiquity, since they are cultivated nowhere else 


\section{De Langhe et al. - The Original Banana Split: Multi-disciplinary implications of the generation of African and Pacific Plantains in Island Southeast Asia}

in the Philippines. The entire P subgroup consists of three types: French plantains with a complete male inflorescence, and the false-horn and horn plantains with respectively a partially or a completely aborted male inflorescence. The three types are molecularly indistinguishable, even though they exhibit such spectacular phenotypic differences (Hippolyte et al. 2012). These differences are probably due to somatic mutations, with the French Plantains as the original type. Moreover, the common 'Philippine' starchy $A A B$ subgroup laknau is genetically close to $P$ cultivars although it had a slightly different edible $A A$ subspecies banksii parent. However, the $P$ were not generated further east, because French $P$ diversity has never been recorded in the New Guinea region.

No MP cultivars have been found among traditional farming or feral populations in the Philippines. They have never been cultivated in the Philippines and were generated elsewhere. As a consequence, it would be expected that the genotype of the edible AA subspecies banksi that contributed to MP would be different to that for P and laknau, which were both likely formed in the Philippines vicinity. Given the M. balbisiana contribution to MP genomes, the $M$. balbisiana parent was most likely taken by people southwards to enable the generation of MP somewhere east of the P/MP divide shown on Figure 2.

\section{Where in the south could MP have been formed?}

The presence of naturalized $M$. balbisiana populations south of the Philippines, even though scarce in present times, can assist with inferring the locations for the generation of interspecific AAB triploids, particularly MP, in the past. The B-genome was introduced southward from the Philippines into a maritime landscape with established and diverse edible AA types. Today, the eastern Indonesian region contains numerous and diverse $A A B$ hybrids (other $\mathrm{P}$ or MP), several of which have not been recorded elsewhere (Hermanto et al. 2014 a,b). In Papua New Guinea, intensive collecting missions have given a reliable picture of local, endemic Musa diversity (Sharrock 1990). Various local AAB have been collected in different places, despite the current scarcity of $M$. balbisiana. Similarly, many AAA have been created and are often accompanied by their edible AA subspecies banksii parents in the New Guinea vicinity. This suggests that mono-AAA as well as interspecific $A A B$ triploidization was probably not a rare event. Comparable interspecific $M$. acuminata $\times$ balbisiana hybridization may have occurred within the entire "edible banksii" area, explaining the generation of local AAB/ABB despite the current scarcity of $M$. balbisiana. However, MP are not cultivated outside New Guinea in the southern part of the PSNG triangle.

\section{Is it possible to restrict the location of MP origin within the vast New Guinea area?}

The probability of MP formation in the Bismarck Archipelago-Solomon Islands area looks higher than for the New Guinea mainland. There is an extraordinarily high diversity of 30 edible AA cultivars in the well-researched province of East New Britain alone, much bigger than in any other province of PNG (Arnaud \& Horry 1997) ${ }^{7}$. All 30 cultivars produce starchy fruit. The inflorescence morphology of many cultivars is quite different from that on mainland $\mathrm{PNG}^{8}$. Similarly, a recent rapid survey of the banana diversity on three of the Solomon Islands reports 12 edible AA (Sachter-Smith 2011) and five AAB cultivars that are typical of MP in Oceania. Moreover, molecular investigation has shown that not one of the many $A A B$ cultivars on mainland New Guinea displays the MP genotype.

In sum, the specific edible AA ancestral to the generation of MP existed in the New Guinea region at the time M. balbisiana was introduced. Based on current $A A B$ diversity and comparisons, the Bismarck Archipelago and Solomon Islands were a likely area of MP origin.

\section{Conclusion based on botanical grounds (Figure 5)}

There are sufficient phytogeographical indications to hypothesize that the basic AAB hybrids of the $P$ and MP subgroups formed in two distinct parts of the PSNG triangle: $\mathrm{P}$ were most probably generated in the Philippines, while MP originated in the New Guinea region, with a high likelihood for the Bismarck Archipelago and Solomon Islands. This botanically-based hypothesis clearly implies two different historical and socio-cultural processes to account for the spatially exclusive generation and dispersal of $P$ and MP cultivar groups.

\section{Multidisciplinary assessment of the split hypothesis}

The hypothesis presented here for the generation of $P$ and MP contributes to an increasingly complex picture of agricultural development within ISEA and the New Guinea region during the mid-to-late Holocene (Barton \& Denham 2011, Denham 2004, 2010, 2011, 2013, Paz 2010). Rather than agricultural practices being predominantly derived from Taiwan, as often portrayed (e.g., Bellwood 2005, Diamond \& Bellwood 2003)9 ${ }^{9}$, different animals, plants, and practices were derived from multiple source regions neighboring ISEA, as well as from within ISEA itself (Denham 2004 to 2013). Significantly, the major staples of cultivation in ISEANG and the Pacific, at least before the widespread adoption of rice cultivation in ISEA from 2000 years ago, were mostly domesticated in ISEANG, whereas

7. Compare with 19 in Madang, 11 in Oro, 11 in the three Highland provinces together; less than 10 in all other provinces.

8. For example, 14 of the 30 cultivars have large horn-like fingers, while similar cultivars are rare or non-existent in the mainland provinces. 


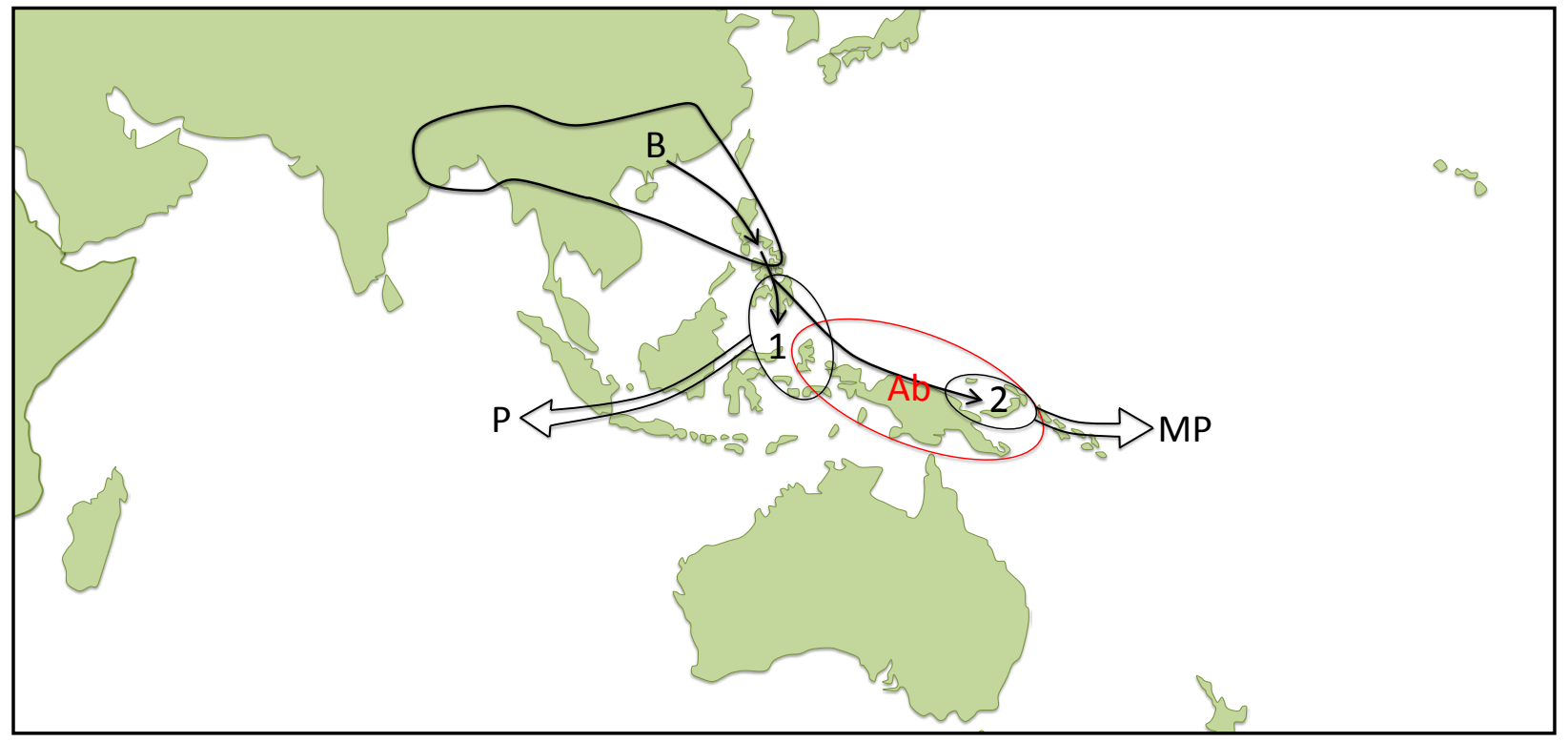

Figure 5. Two different areas (1,2) where the generation of triploid hybrids $(A A B)$ as plantain $(P)$ and maoli-popo ulu (MP) took place from (B) Musa balbisiana Colla, and (Ab) Musa acuminata subsp. bansii (F. Muell.) Simmonds.

the major animal domesticates all ultimately originate on mainland Eurasia.

The emerging complexity is most clearly seen with respect to the domestic pig (Sus scrofa L., 1758). Archaeological remains of domestic-type pigs from northern Luzon date to at least 4000 years ago (Piper et al. 2009). These pigs are thought to derive from interaction across the Batanes Strait from that time, which is also associated with the introduction of red-slipped pottery, rice, and other material cultural traits. However, pigs from the Taiwan-Philippines region are not the same as those found across southern ISEA and in the Pacific; pigs in the latter region trace their proximal origins westward to the Malay Peninsula rather than Taiwan (Larson et al. 2007). Consequently, an out-ofTaiwan sweep through ISEA and outwards into the Pacific does not accord with the pig evidence, which indicates multiple source regions and different dispersal trajectories.

The historical reconstruction for the generation of $\mathrm{P}$ and MP contributes to the increasingly complex picture emerging for early cultivation and plant domestication in the ISEA and New Guinea regions. This reconstruction also brings to light significant historical processes which are currently poorly understood.

Firstly, the proposed movement of $M$. balbisiana from mainland SEA, plausibly from Vietnam, to the Philippines indicates maritime contacts by at least 3100 years ago. Musa balbisiana must have already been introduced to ISEA by this date in order to enable the generation and spread of MP into the Pacific with Lapita-bearing colonists. Direct contact between mainland and island SEA at that time is not clear in the archaeological record at present (cf. Bulbeck 2008). However, the maritime introduction of $M$. balbisiana to the Philippines should not be so surprising; the Philippines were already enmeshed in maritime interactions with Taiwan (Piper et al. 2009) and the Mariana Islands (Hung et al. 2011), as well as plausibly other regions within ISEA (Donohue \& Denham 2010), by c. 3500 years ago.

Secondly, the multi-directionality of interaction within ISEA, as well as with neighboring regions, is exhibited by the introduction of $M$. balbisiana to Taiwan from the Philippines. In contrast to recurrent portrayals (Bellwood 2007, Diamond 2000), material cultural elements were not just brought across the Batanes Strait from Taiwan to the Philippines. Maritime interaction was not one-way. The evidence presented and reconstruction proposed here give further evidence that suggests movements across the Batanes Strait were two-way and that cultivation practices and plants from ISEA contributed to agriculture in Taiwan. At present the precise timing of introduction of $M$. balbisiana to Taiwan is unknown.

9. According to this perspective, the Austronesian speaking farmer-voyagers moved southwards from Taiwan to the Philippines, onwards to the reminder of ISEA, and then eastwards to the Bismarck Archipelago, which has long been considered the home of Oceanic languages and the Lapita culture (Bellwood 2007, though see Donohue \& Denham 2010, 2012, and Specht et al. 2014 for alternatives). 


\section{De Langhe et al. - The Original Banana Split: Multi-disciplinary implications of the generation of African and Pacific Plantains in Island Southeast Asia}

Thirdly, and following from the above, the generation of $P$ and MP in ISEA likely required the respective movements of edible AA northwestward from New Guinea to the Philippines, or possibly to Wallacea (Denham \& Donohue 2009), and of $M$. balbisiana southeastward from the Philippines to the Bismarck Archipelago and the Solomon Islands [following the trajectory mapped by Mahdi (1994a, b), mapping non-Austronesian words that are implicated in the spread of Austronesian languages]. Consequently, the generation of $\mathrm{P}$ and MP clearly demonstrate the multidirectional character of maritime interactions within ISEA and the circum-New Guinea regions before c. 3100 years ago. The subsequent dispersals of $P$ westward across the Indian Ocean and of MP eastward into the Pacific demonstrate the significance of plant domesticates from ISEA and New Guinea to the development of agriculture across the Old World tropics.

The geographically exclusive generation and dispersal of $\mathrm{P}$ and MP, referred to here as the "original banana split," indicates intra-regional complexity within the ISEA-New Guinea region before 3000 years ago. Although there are comparable archaeological, genetic, and linguistic indicators of complex movements of plants, people, and things with ISEA-NG, these do not exhibit the same geographical and temporal trajectories proposed here for banana cultivars. Consequently, the original banana split sheds light on socio-spatial processes within the broader ISEANG region that are currently largely invisible and should act as a spur to further multi-disciplinary research.

\section{Conclusion}

Multidisciplinary evidence for the generation of $A A B$ plantain and $A A B$ maoli-popo ulu cultivars suggests (1) multiple source regions: $M$. balbisiana was introduced to the Philippines from mainland SEA, whereas $M$. acuminata subspecies banksii originated in the New Guinea vicinity; (2) multiple locations of hybridization: $P$ in the Philippines and MP in the Bismarck Archipelago and Solomon Islands; and (3) multiple and exclusive dispersal trajectories: $P$ westward around the Indian Ocean and MP eastward into the Pacific. Rather than conforming to a monolithic out-of-Taiwan model of Neolithic dispersal-in which languages, people, and material culture spread together as a single event-the generation of African and Pacific plantains confirms interpretations that highlight how animal and plant domesticates, as well as material cultural items, differentially coalesced in ISEA and New Guinea over several millennia in the late Holocene (following Donohue \& Denham 2010 and Specht et al. 2014). In some times and some places intrusive traits came into the region together in their dispersal, but there was no regional priority; different domesticates came into ISEA from Taiwan, mainland SEA, and New Guinea, while others emerged within ISEA itself and spread from there.

\section{Literature Cited}

Allen, P.H. 1965. Annotated index of Philippine bananas. Philippine Agriculture 49(9):310-411.

Argent, G.C.G. 1976. The wild bananas of Papua New Guinea. Notes of the Royal Botanical Gardens, Edinburgh 35:77-114.

Arnaud, E. \& J.P. Horry. 1997. Editors of Musalogue: A catalogue of Musa germplasm. Papua New Guinea collecting missions, 1988-1989. International Network for the Improvement of Banana and Plantain, Montpellier, France.

Barton, H. \& T.P. Denham. 2011. Prehistoric vegeculture and social life in Island Southeast Asia and Melanesia. Pp. 17-25 in Why Cultivate? Anthropological and archaeological approaches to foraging-farming transitions in Southeast Asia. Edited by G. Barker \& M. Janowski. McDonald Institute Monographs, McDonald Institute for Archaeological Research, Cambridge, U.K.

Bellwood, P. 2005. First Farmers. Blackwell, Oxford, U.K.

Bellwood, P. 2007. Prehistory of the Indo-Malaysian Archipelago. Revised edition. Australia National University, EPress, Canberra, Australia.

Bulbeck, D. 2008. An integrated perspective on the Austronesian diaspora: The switch from cereal agriculture to maritime foraging in the colonisation of Island Southeast Asia. Australian Archaeology 67:31-51.

Carreel, F. 1994. Etude de la diversité génétique des bananiers (genre Musa) à l'aide des marqueurs moléculaires. Ph.D. thesis, Institut National Agronomique, Paris, France.

Carreel, F., D. Gonzalez de Leon, P.J.L. Lagoda, C. Lanaud, C. Jenny, J.P. Horry \& H. Tézenas du Montcel. 2002. Ascertaining maternal and paternal lineage within Musa by chloroplast and mitochondrial DNA RFLP analyses. Genome 45:679-692. dx.doi.org/10.1139/g02-033

Chiu H.-L., S.-I. Lee, C.-L. Yeh, C.-T. Shii \& C.-R. Yeh. 2007. Musa balbisiana L. A. Colla, A Newly Naturalized Wild Banana in Taiwan. Journal of Taiwan Agricultural Research 56(3):215-223.

Constantine, D.R. 2007. The truth about Musa basjoo. www.users.globalnet.co.uk/ drc/the truth about musa basjoo.htm.

Daniells, J. 2007. Consultancy report on Characterization of Banana Varieties in Two Collections on Makira, Solomon Islands. http://bit.ly/WZme7V 
De Langhe, E. 2007. The establishment of traditional plantain cultivation in the African rain forest: A working hypothesis. Pp. 361-370 in Rethinking Agriculture: Archaeological and ethnoarchaeological perspectives. Edited by T.P. Denham, J. Iriarte \& L. Vrydaghs. Left Coast Press, Walnut Creek, California, U.S.A.

De Langhe, E. \& P. de Maret. 1999. Tracking the banana: Its significance in early agriculture. Pp. 377-396 in The Prehistory of Food: Appetites for change. Edited by C. Gosden \& J. Hather. Routledge, New York, New York, U.S.A.

De Langhe, E. \& R.V. Valmayor. 1979. French plantains in Southeast Asia. IBPGR Newsletter for South-east Asia:34.

De Langhe, E., L. Vrydaghs, P. de Maret, X. Perrier \& T.P. Denham. 2009. Why bananas matter. Ethnobotany $R e-$ search \& Applications 7:165-177.

dx.doi.org/10.17348/era.7.0.165-177

Denham, T.P. 2010. From domestication histories to regional prehistory: Using plants to re-evaluate early and mid-Holocene interaction between New Guinea and Southeast Asia. Food and History 8:3-22. dx.doi. org/10.1484/J.FOOD.1.100971

Denham, T.P. 2011. Early agriculture and plant domestication in New Guinea and Island Southeast Asia. Current Anthropology 52(S4):S379-S395. dx.doi. org/10.1086/658682

Denham, T.P. 2013. Early farming in Island Southeast Asia: An alternative hypothesis. Antiquity 87:250-257. dx.doi.org/10.1017/S0003598X00048766

Denham, T.P., C. Bronk Ramsey \& J. Specht. 2012. Dating the appearance of Lapita pottery in the Bismarck Archipelago and its dispersal to Remote Oceania. Archaeology in Oceania 47:39-46. dx.doi.org/10.1002/j.1834-4453.2012. tb00113.x

Denham, T.P. \& M. Donohue. 2009. Pre-Austronesian dispersal of banana cultivars west from New Guinea: Linguistic relics from eastern Indonesia. Archaeology in Oceania 44:18-28. dx.doi.org/10.1002/j.1834-4453.2009. tb00041.x

Denham, T.P., M. Donohue \& S. Booth. 2009. Revisiting an old hypothesis: Horticultural experimentation in northern Australia. Antiquity 83:634-648. dx.doi.org/10.1017/ $\underline{\text { S0003598X00098884 }}$

Denham, T.P., S.G. Haberle \& C. Lentfer. 2004. New evidence and interpretations for early agriculture in Highland New Guinea. Antiquity 78:839-857.
Denham, T.P., S.G. Haberle, C. Lentfer, R. Fullagar, J. Field, M. Therin, N. Porch \& B. Winsborough 2003. Origins of agriculture at Kuk Swamp in the Highlands of New Guinea. Science 301:189-193. dx.doi.org/10.1126/science. 1085255

Diamond, J. 2000. Taiwan's gift to the world. Nature 403:709-710. dx.doi.org/10.1038/35001685

Diamond, J. \& P. Bellwood. 2003. Farmers and their languages: The first expansions. Science 300:597-603. dx.doi.org/10.1126/science. 1078208

Donohue, M. 2007. The Papuan language of Tambora. Oceanic Linguistics 46(2):520-537. dx.doi.org/10.1353/ ol.2008.0014

Donohue, M. \& T.P. Denham. 2009. Banana (Musa spp.) domestication in the Asia-Pacific region: Linguistic and archaeobotanical perspectives. Ethnobotany Research \& Applications 7:293-332. dx.doi.org/10.17348/era.7.0.293$\underline{332}$

Donohue, M. \& T.P. Denham. In press a. The role of contact and language shift in the spread of Austronesian languages across Island Southeast Asia. In Language Dispersal, Diversification, and Contact: A global perspective. Edited by P. Muysken, J-M. Hombert \& M. Crevels. Oxford University Press, Oxford, U.K.

Donohue, M. \& T.P. Denham. In press b. Becoming Austronesian: Mechanisms of language dispersal across southern Island Southeast Asia. In Austronesian Undressed. Edited by D. Gil \& J. McWhorter. Pacific Linguistics, Canberra, Australia.

Donohue, M. 2013. Towards a Papuan history of languages. Language and Linguistics in Melanesia 31(1):24-41. www.langlxmelanesia.com/issues.htm.

Haberle, S.G., C. Lentfer, S. O'Donnell \& T.P. Denham. 2012. The palaeoenvironments of Kuk Swamp from the beginnings of agriculture in the highlands of Papua New Guinea. Quaternary International 249:129-139. dx.doi. org/10.1016/j.quaint.2011.07.048

Hendrickx, K. 2007. The Origins of Banana-fiber Cloth in the Ryukyus, Japan. Leuven University Press, Leuven, Belgium.

Hermanto, C., H.S. Edison, F. Nasution, Riska, E. Malia, Nofriarjasri, J. Daniells, A. Sutanto \& Y. Hilman. 2014a. Triangle Banana Exploration Report, North Sulawesi and North Maluku, Indonesia, 6-24 October 2012. Bioversity, Montpellier, France.

Hermanto, C., A. Sutanto, H.S. Edison, Riska, Alfons, E. Hosang, J. Daniells \& Y. Hilman. 2014b. Triangle Banana 


\section{De Langhe et al. - The Original Banana Split: Multi-disciplinary implications of the generation of African and Pacific Plantains in Island Southeast Asia}

Exploration Report, Central Maluku and Lesser Sunda Islands, Indonesia, 16 February-3 March 2013. Bioversity, Montpellier, France.

Hippolyte, I., C. Jenny, L. Gardes, F. Bakry, R. Rivallan, V. Pomies, P. Cubry, K. Tomekpe, A.M. Risterucci, N. Roux, M. Rouard, E. Arnaud, M. Kolesnikova-Allen \& X. Perrier. 2012. Foundation characteristics of edible Musa triploids revealed from allelic distribution of SSR markers. Annals of Botany 109:937-951. dx.doi.org/10.1093/aob/mcs010

Horry, J.P. \& M. Jay. 1988. Distribution of anthocyanins in wild and cultivated banana varieties. Phytochemistry 27:2667-2672. dx.doi.org/10.1016/0031-9422(88)87040-7

Hung, H-C., M.T. Carson, P. Bellwood, F.Z. Campos, P.J. Piper, E. Dizon, M. Bolunia, M. Oxenham \& C. Zhang. 2011. The first settlement of Remote Oceania: The Philippines to the Marianas. Antiquity 85:909-926. dx.doi. org/10.1017/S0003598X00068393

Hung, H.-C., Y. lizuka, P. Bellwood, K.D. Nguyen, B. Bellina, P. Silapanth, E. Dizon, R. Santiago, I. Datan \& J.H. Manton. 2007. Ancient jade maps 3000 years of prehistoric exchange in Southeast Asia. Proceedings of the National Academy of Sciences 104:19745-19750. dx.doi. org/10.1073/pnas.0707304104

Kennedy, J. 2008. Pacific bananas: Complex origins, multiple dispersals? Asian Perspectives 47:75-94. dx.doi. org/10.1353/asi.2008.0004

Kennedy J. 2009. Bananas and people in the homeland of genus Musa: Not just pretty fruit. Ethnobotany Research \& Applications 7:179-197. dx.doi.org/10.17348/ era.7.0.179-197

Larson, G., T. Cucchi, M. Fujita, E. Matisoo-Smith, J. Robins, A. Anderson, B. Rolett, M. Spriggs, G. Dolman, T-H. Kim, N.T.D. Thuy, E. Randi, M. Doherty, R.A. Due, R. Bollt, T. Djubiantono, B. Griffin, M. Intoh, E. Keane, P. Kirch, K-T. Li, M. Morwood, L.M. Pedrina, P.J. Piper, R.J. Rabett, P. Shooter, G. Van den Bergh, E. West, S. Wickler, J. Yuan, A. Cooper \& K. Dobney. 2007. Phylogeny and ancient DNA of Sus provides insights into Neolithic expansion in Island Southeast Asia and Oceania. Proceedings of the National Academy of Sciences 104:4834-4839. dx.doi.org/10.1073/pnas.0607753104

Lebot, V., M.K. Aradhya, R.M. Manshardt \& B.A. Meilleur. 1993. Genetic relationships among cultivated bananas and plantains from Asia and the Pacific. Euphytica 67:163-175. dx.doi.org/10.1007/BF00040618

Lentfer, C. 2009. Tracing domestication and cultivation of bananas from phytoliths: An update from Papua New
Guinea. Ethnobotany Research and Applications 7:247270. dx.doi.org/10.17348/era.7.0.247-270

Mahdi, W. 1994a. Some Austronesian maverick protoforms with culture-historical implications. I. Oceanic Linguistics 33(1):167-229. dx.doi.org/10.2307/3623005

Mahdi, W. 1994b. Some Austronesian maverick protoforms with culture-historical implications. II. Oceanic Linguistics 33(2):431-490. dx.doi.org/10.2307/3623137

Markey, P. 2009. Musa balbisiana var. liukiuensis. A not so newly naturalized wild banana in Taiwan. Trebrown Nurseries Blog. www.trebrown.com/articles/blog/musa-balbisiana-var-liukiuensis/

Mbida, C.M., H. Doutrelepont, L. Vrydaghs, R.L. Swennen, R.J. Swennen, H. Beeckman, E. de Langhe \& P. de Maret. 2001. First archaeological evidence of banana cultivation in central Africa during the third millennium before present. Vegetation History and Archaeobotany 10:1-6. dx.doi.org/10.1007/PL00013367

Paz, V. 2010. Comment. Current Anthropology 51:244.

Perrier, X., F. Bakry, F. Carreel, C. Jenny, J.-P. Horry, V. Lebot \& I. Hippolyte. 2009. Combining biological approaches to shed light on the evolution of edible bananas. Ethnobotany Research \& Applications 7:199-216. dx.doi. org/10.17348/era.7.0.199-216

Perrier X., E. De Langhe, M. Donohue, C. Lentfer, L. Vrydaghs, F. Bakry, F. Carreel, I. Hippolyte, J-P. Horry, C. Jenny, V. Lebot, A-M. Risterucci, K. Tomekpe, H. Doutrelepont, T. Ball, J. Manwaring, P. de Maret \& T. Denham. 2011. Multidisciplinary perspectives on banana (Musa spp.) domestication. Proceedings of the National Academy of Science 108(28):11311-11318. dx.doi.org/10.1073/ pnas. 1102001108

Piper, P.J., H.-C. Hung, F.Z. Campos, P. Bellwood \& R. Santiago. 2009. A 4000 year-old introduction of domestic pigs into the Philippine Archipelago: Implications for understanding routes of human migration through Island Southeast Asia and Wallacea. Antiquity 83:687-695. dx.doi.org/10.1017/S0003598X00098914

Reid, L. 1994. Unraveling the linguistic histories of Philippine negritos. Pp. 443-475 in Language Contact and Change in the Austronesian World. Edited by T.E. Dutton \& D.T. Tryon. Mouton de Gruyter, Berlin, Germany. $\underline{\mathrm{dx} . \mathrm{doi}}$. org/10.1515/9783110883091.443

Sachter-Smith, G. 2011. Bananas of the Solomon Islands. Bioversity International, Montpellier, France. 
Sharrock, S. 1990. Collecting Musa in Papua New Guinea. Pp. 140-157 in Identification of Genetic Diversity in the Genus Musa: Proceedings of an International Workshop held at Los Baños, Philippines, 5-10 September 1988. Edited by R.L. Jarret. International Network for the Improvement of Banana and Plantain, Montpellier, France.

Simmonds, N.W. 1956a. A banana collection expedition to South East Asia and the Pacific. Tropical Agriculture, Trinidad 33(4).

Simmonds, N.W. 1956b. Botanical results of the banana collecting expedition, 1954-5. Kew Bulletin 1956(3):463490. dx.doi.org/10.2307/4109131

Simmonds, N.W. 1959. Bananas. Longmans, London, U.K.

Simmonds, N.W. 1962. The Evolution of the Bananas. Longmans, London, U.K.

Soares, P., T. Rito, J. Trejaut, M. Mormina, C. Hill, E. Tinkler-Hundal, M. Braid, D.J. Clarke, J.-H. Loo, N. Thomson, T. Denham, M. Donohue, V. Macaulay, M. Lin, S. Oppenheimer \& M.B. Richards. 2011. Ancient voyaging and Polynesian origins. The American Journal of Human Genetics 88:239-247. dx.doi.org/10.1016/j.ajhg.2011.01.009

Specht, J., T.P. Denham, J. Goff \& J.E. Terrell. 2014. Deconstructing the Lapita Cultural Complex in the Bismarck
Archipelago. Journal of Archaeological Research 22:89140. dx.doi.org/10.1007/s10814-013-9070-4

Sutanto, E. \& H.S. Edison, 2005. Deskripsi Pisang Indonesia. Balai Pnelitian Tanamam Buah Tropika, Badan Penelitian dan Pengembangan Pertanian. Departemen Pertanian, Jakarta, Indonesia.

Terrell, J.E. 2004. The "Sleeping Giant" hypothesis and New Guinea's place in the prehistory of Greater Near Oceania. World Archaeology 36:601-609. dx.doi. org/10.1080/0043824042000303782

Valmayor, R.V., F.N. Rivera \& F.M. Lomuljo. 1981. Philippine Banana Cultivar Names and Synonyms. National Plant Resource Laboratory, Institute of Plant Breeding, University of the Philippines, Los Baños, Philippines.

Valmayor, R.V., R.R.C. Espino \& O.C.Pascua. 2002. The Wild and Cultivated Bananas of the Philippines. Philippine Agriculture and Resources Research Foundation, Inc., Los Baños, and Bureau of Agricultural Research, Laguna, Philippines.

Wright, D., T.P. Denham, D. Shine \& M. Donohue 2013. An archaeological review of western New Guinea. Journal of World Prehistory 26:25-73. dx.doi.org/10.1007/ s10963-013-9063-8 